\title{
Mitos y realidades sobre alergia a vacunas
}

\section{Myths and facts about vaccine allergy}

\author{
Liliana Guevara-Saldaña, Ana María Calle-Álvarez, Ruth Helena Ramírez-Giraldo, \\ Carlos Chinchilla-Mejia, Ricardo Cardona-Villa • Medellín (Colombia)
}

\section{Resumen}

En América Latina existen varios mitos sobre las vacunas convencionales, principalmente en pacientes con alergia alimentaria. Este artículo pretende revisar algunos de los mitos existentes, sus orígenes y proponer un abordaje clínico más adecuado. Así mismo, se propone unas directrices acerca del manejo de los pacientes alérgicos que requieren ser vacunados. Finalmente, no se debería dejar de suministrar las vacunas a los pacientes con antecedentes de alergia alimentaria, donde la mayoría de veces se requiere el concepto del médico especialista en alergología. (Acta Med Colomb 2019; 44: 96-102).

Palabras clave: vacunas, alergia alimentaria, mitos.

\begin{abstract}
In Latin America there are several myths about conventional vaccines, mainly in patients with food allergy. This article aims to review some of the existing myths, their origins and propose a more adequate clinical approach. Likewise, some guidelines about the management of allergic patients that require vaccination are proposed. Finally, in patients with a history of food allergy, where the concept of an allergy specialist is most of the time required, the supply of vaccines should not be interrupted. (Acta Med Colomb 2019; 44: 96-102).
\end{abstract}

Keywords: vaccines, food allergy, myths.

Dres. Liliana Guevara-Saldaña, Ana María Calle-Álvarez, Ruth Helena Ramírez-Giraldo, Carlos Chinchilla-Mejía, Ricardo CardonaVilla: Grupo de Alergología Clínica y Experimental, IPS Universitaria, Universidad de Antioquia. (Medellín, Colombia).

Correspondencia: Dr. Ricardo Cardona-Villa. Medellín (Colombia).

E-mail: rcv2016udea@gmail.com Recibido: 18/IV/2018 Aceptado: 22/III/2019

\section{Introducción}

Según la Organización Mundial de la Salud (OMS) las vacunas son productos biológicos destinados a generar inmunidad contra una enfermedad, estimulando la producción de anticuerpos (1). Las vacunas pueden contener uno o más antígenos que luego de ser administrados generan una respuesta inmune específica, similar a lo que ocurre tras una infección natural, pero con un menor riesgo para el paciente. Esta respuesta inmune protege al individuo frente a futuras exposiciones al microorganismo (2-4).

El método habitual para administrar las vacunas es la inyección, aunque algunas se administran por vía nasal u oral. Desde la perspectiva microbiológica y según el componente antigénico involucrado, las vacunas están compuestas por virus o bacterias y se dividen en vacunas vivas atenuadas y vacunas no vivas o inactivas. Independiente de su composición, se pueden administrar diferentes vacunas de forma simultánea en una misma visita o de forma separada, sin afectar la inmunogenicidad del tratamiento ni aumentar la reactividad entre vacunas (2).

Desde finales del siglo XVIII con el descubrimiento de la vacuna contra la viruela por Edward Jenner, la vacunación ha sido considerada la estrategia de salud pública más costoefectiva para la prevención de enfermedades infecciosas. Se calcula que la vacunación previene unos dos a tres millones de muertes anuales, pero mejorando la cobertura mundial esta cifra llegaría a los 4.5 millones de muertes evitables (1). Existe evidencia sobre los beneficios de la vacunación masiva, que ha llevado a la erradicación de la viruela en 1979 considerado uno de los mayores logros de la humanidad; la disminución en $99 \%$ de la incidencia mundial de la poliomielitis (1), en Colombia ya se habla de erradicación, y a nivel mundial se observa la reducción de los casos de enfermedad, discapacidad y muerte por difteria, tétanos y en especial de sarampión $(5,6)$.

Uno de los principales objetivos de la OMS es aumentar la conciencia sobre la inmunización y su demanda y mejorar los servicios de vacunación, de modo que todas las personas, vivan donde vivan, puedan estar protegidas frente a enfermedades potencialmente mortales. Se estima que 19.4 millones de lactantes de todo el mundo aún no reciben las vacunas básicas, por limitaciones en los esquemas de vacunación de cada país y por creencias religiosas y culturales (1). 
Los argumentos religiosos contra la vacunación se conocen desde hace muchos años y, a finales del siglo XIX, paralelo a la implementación de los planes de vacunación masiva, surgen los primeros movimientos antivacunas en Reino Unido y Estados Unidos, los cuales han perdurado hasta la fecha. En Reino Unido, la vacuna triple viral fue objeto de controversia después de la publicación en 1998 en la revista The Lancet, de un artículo de Andrew Wakefield y colaboradores sobre un estudio que incluía 12 niños con trastornos del espectro autista, cuyos síntomas iniciaron poco después de administrarles la vacuna (7). Numerosos estudios han refutado una asociación entre las vacunas y el autismo y otros desórdenes del desarrollo neurológico; sin embargo la preocupación entre los cuidadores aún persiste (8). A pesar de no contar con la suficiente evidencia científica, esta publicación recibió gran atención por parte de los medios de comunicación y llevó a una disminución en los índices de vacunación de los países desarrollados. Desde entonces se han presentado brotes de sarampión en sitios donde ya se consideraba erradicada la enfermedad, y en donde la mayoría de los casos los individuos no estaban vacunados (9).

\section{Mecanismos de la respuesta alérgica a vacunas}

Las reacciones adversas relacionadas con las vacunas aumentan los temores sobre la administración de estos medicamentos biológicos. Aunque no se conoce con precisión la prevalencia de las reacciones de hipersensibilidad a vacunas, puede existir una sobre estimación de dichas reacciones, debido a que las manifestaciones clínicas que ocurren de manera simultánea con la vacunación como la ansiedad, las respuestas vasovagales o las reacciones locales en el sitio de la aplicación, suelen confundirse con reacciones alérgicas.

Las reacciones alérgicas explican la minoría de los eventos adversos tras la vacunación. Un estimado aproximado de las reacciones alérgicas a vacunas incluyendo las reacciones de hipersensibilidad inmediatas, varían de un caso en 50000 a un caso en 1000000 de dosis administradas $(10,11)$. Siendo las reacciones graves como la anafilaxia, muy raras, aproximadamente un caso en 100000 a un caso en 1000000 de dosis administradas y las muertes mucho más bajas (12-14).

Las reacciones de hipersensibilidad pueden ocurrir por los antígenos propios de las vacunas, como fracciones de microorganismos o toxinas modificadas (toxoides); el medio residual usado para crecimiento de los microorganismos (ejemplo: leche, huevo y levadura); los estabilizantes y preservantes usados para extender la vida media de la vacuna (ejemplo: gelatina); a los adyuvantes que aumentan la respuesta inmune de la vacuna (ejemplo: aluminio y timerosal); a excipientes tales como antibióticos que previenen el crecimiento bacteriano (ejemplo: neomicina) y a otras sustancias como el látex. La mayoría de estos componentes están presentes en pequeñas cantidades, que por lo general, no inducen reacciones de hipersensibilidad (15).
Las reacciones alérgicas a las vacunas son en su mayoría de dos tipos, las reacciones de hipersensibilidad tipo I mediadas por inmunoglobulina $\mathrm{E}$, que se presentan de forma inmediata y las reacciones de hipersensibilidad tipo IV o mediadas por células, con una presentación mucho más tardía. A su vez, estas reacciones se pueden clasificar en reacciones sistémicas y locales (Figura 1) $(9,16)$.

\section{Reacciones sistémicas}

Las reacciones sistémicas mediadas por inmunoglobulina $\mathrm{E}$ (IgE), típicamente ocurren en la primera hora tras la vacunación. Los síntomas más comunes son la urticaria y el angioedema, aunque pueden presentarse con menor frecuencia síntomas como: congestión nasal, tos, estridor, sibilancias, disnea, vómito, dolor abdominal, diarrea e hipotensión (16). La frecuencia de presentación en niños y adolescentes en promedio es de un caso en 50000 a un caso en 1000000 por dosis aplicadas. La anafilaxia es la forma más grave de las reacciones inmediatas, se reporta alrededor de un caso por 1000000 dosis administradas y cuadros clínicos como el síncope vasovagal puede confundirse con ésta, por lo cual, se deben tener en cuenta como diagnóstico diferencial (11, 15-17).

Los antimicrobianos como: gentamicina, tetraciclina, neomicina, estreptomicina y polimixina B, son usados durante los procesos de producción para prevenir el crecimiento de bacterias u hongos y están presentes en pequeñas cantidades. Las trazas de antimicrobianos podrían teóricamente causar anafilaxia en pacientes sensibilizados; sin embargo, las reacciones de hipersensibilidad inmediatas no se han documentado claramente. Por ahora el antecedente de anafilaxia a neomicina es una contraindicación para la aplicación de vacunas que contienen este antibiótico $(4,8,9)$.

Las reacciones sistémicas que no son mediadas por IgE son los eventos más comunes luego de la vacunación, estos incluyen: fiebre, brote cutáneo, irritabilidad, malestar, cefalea, dolor muscular y síncope. Las manifestaciones cutáneas como la erupción maculopapular, urticaria y angioedema de presentación tardía, con frecuencia ocurren a las pocas

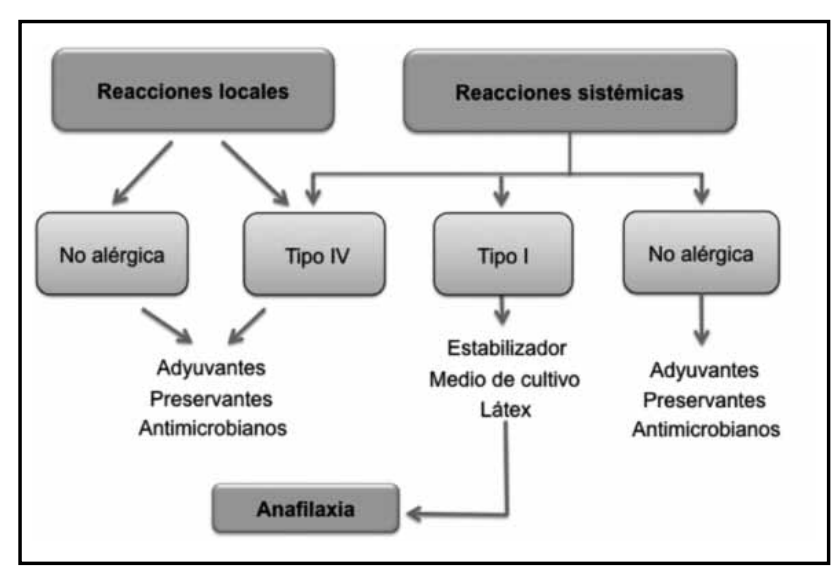

Figura 1. Clasificación de las reacciones a vacunas. 
horas de la administración de la vacuna y puede explicarse por una activación inespecífica del sistema inmune y a la degranulación del mastocito $(15,18)$.

\section{Reacciones locales}

Las reacciones locales son los eventos adversos más frecuentes, siendo las reacciones locales no alérgicas las más comunes; éstas incluyen síntomas como: dolor, eritema, edema y prurito, en el sitio de aplicación de la vacuna. Las reacciones locales extensas son menos comunes e incluyen: nódulos subcutáneos y eccema que pueden tardar semanas en resolver; éstos se presentan principalmente con vacunas que contienen hidróxido de aluminio (19). La técnica de aplicación de la vacuna se relaciona con la aparición de estas reacciones especialmente en menores de tres años y la ocurrencia de estos eventos no contraindica futuras dosis $(11,15,16,18)$. Por otra parte, la mayoría de las reacciones locales alérgicas son secundarias a reacciones de hipersensibilidad tipo IV o tardía que no llevan a una gran morbilidad. Generalmente inician después de las 24 horas de la vacunación con un pico de presentación a las 72 horas, resuelven en dos a tres días y ocurren con mayor frecuencia posterior a la aplicación de vacunas que contienen timerosal, aluminio y agentes antimicrobianos $(20,21)$.

A pesar de la efectividad y seguridad de las vacunas, su uso continúa siendo cuestionado por algunos grupos poblacionales. Debido a que las enfermedades prevenibles con vacunas actualmente no son prevalentes, muchos padres no están familiarizados con las enfermedades y sus secuelas y podrían no percibirlas como nocivas. Al mismo tiempo las vacunas son los únicos agentes farmacológicos administrados a niños sanos que previene futuras enfermedades, en este contexto, perciben un riesgo mayor con la vacuna que el riesgo que implica la enfermedad por sí misma y algunos padres optan por retrasar o evitar las vacunas por completo (22).

Esto ha llevado al surgimiento de mitos que han logrado impactar en los sistemas de vacunación masiva de salud pública, principalmente en los países en desarrollo, disminuyendo la inmunidad en rebaño y reportándose brotes epidemiológicos de enfermedades que en algunos casos ya se consideraban erradicadas; como es el caso del sarampión $(4,23)$. Debido a esto, las autoridades han tenido que implementar medidas más allá de las campañas de información como la obligatoriedad de la vacunación. Algunos de estos mitos se discutirán a continuación:

\section{- Mito número 1}

"Los niños con alergia al huevo no pueden recibir la vacuna contra la influenza y triple viral".

Discusión. La vacuna contra la influenza se prepara en un fluido alantoico en embriones de huevo de pollo y por lo tanto, pueden contener pequeñas cantidades de proteínas de huevo principalmente ovoalbúmina, cuya cantidad puede variar según el fabricante y el lote de la vacuna. Es por esto que el uso de la vacuna contra la influenza en los pacientes alérgicos al huevo ha generado grandes preocupaciones a lo largo del tiempo. Sin embargo, muchos estudios han evaluado la seguridad de la vacuna, incluyendo pacientes con alergia severa al huevo y aunque algunos sujetos desarrollaron reacciones cutáneas leves como urticaria generalizada, no presentaron reacciones anafilácticas $(11,15,16)$.

La vacuna contra la influenza es la única que cambia habitualmente su formulación basándose en las cepas de influenza que se proyectan circulan en cada temporada, ya que el virus cambia rápidamente sus características antigénicas. Existen dos tipos de vacunas, las vacunas inactivas y las vacunas con cepas vivas atenuadas; recientemente se ha incluido la vacuna recombinante. En Colombia está disponible la vacuna trivalente de virus inactivo que contiene tres virus, dos de tipo A (H3N2 y H1N1) y uno de tipo B. El riesgo de una reacción de hipersensibilidad inmediata es dos veces mayor con las vacunas de virus vivos atenuados que con las de virus inactivos (15). El contenido de ovoalbúmina en las vacunas contra la influenza varía entre 0.2 a $\mu \mathrm{g} / \mathrm{mL} /$ Ml (24). Según el contenido se distinguen tres categorías:

- Vacuna de influenza recombinante: no contiene ovoalbúmina por lo cual es segura. Se encuentra aprobada en Estados Unidos para personas entre los 18 y 49 años; sin embargo, no se encuentra disponible en Colombia.

- Vacuna trivalente y cuadrivalente inactivas: contienen bajo contenido de ovoalbúmina (menor de 0.12 $\mathrm{mcg} / \mathrm{mL}$ ). Pueden ser administradas de forma segura en pacientes con alergia al huevo, incluyendo aquellos con enfermedad severa, a partir de los 6 meses de vida (1) $(25,26)$.

- Vacunas trivalente y cuadrivalente de virus vivo atenuado (LAIVs): son las que tienen el contenido más alto de ovoalbúmina reportado en el paquete del inserto $(0.24 \mathrm{mcg}$ por $0.2 \mathrm{~mL} / \mathrm{dosis})$, pero laboratorios independientes han encontrado que en realidad el contenido es mucho más bajo (entre 0.00013 y $0.0017 \mathrm{mcg}$ por 0.2 $\mathrm{mL} /$ dosis) (27). En los Estados Unidos estas vacunas están contraindicadas en los pacientes con alergia al huevo, sin embargo el estudio SNIFFLE no encontró reacciones sistémicas con su aplicación en niños alérgicos al huevo y solo en $1.6 \%$ de 1242 dosis administradas se presentaron reacciones leves y autolimitadas (28). En los estudios de seguridad con este tipo de vacunas se ha encontrado que los niños entre 6 a 23 meses de edad tienen un mayor riesgo de presentar sibilancias, a diferencia de los niños entre los dos a cinco años, en los cuales no se ha encontrado esta relación, por lo anterior, se considera segura su administración en este rango de edad, incluyendo pacientes con asma leve a moderada o con antecedentes de sibilancias; los datos en asma severa son aún limitados $(11,16)$. 
La vacuna triple viral o vacuna contra sarampión, rubéola y parotiditis, se prepara en cultivos de fibroblastos de embrión del pollo, y por tanto contiene cantidades casi imperceptibles o trazas de ovoalbúmina $(0.1 \mathrm{ng} / \mathrm{mL})(15,16,18)$.

Conclusión. La vacuna de la influenza puede ser usada independientemente de la severidad de la alergia a huevo. Según el Comité Asesor Canadiense de Inmunización (NACI) se recomienda que los pacientes con alergia al huevo sean vacunados contra la influenza usando la vacuna trivalente, con la dosis completa y sin necesidad de realizar pruebas cutáneas previamente (29).

La vacuna triple viral se considera segura en los pacientes con alergia al huevo, éstos pueden recibir la dosis completa de independientemente de la severidad de la reacción que hayan presentado con el huevo y no se considera necesario realizar pruebas cutáneas en estos pacientes $(30,31)$.

\section{- Mito número 2}

"La vacuna contra la fiebre amarilla es innecesaria y está contraindicada en los pacientes con alergia al huevo"

Discusión. La vacuna contra la fiebre amarilla por lo general es asequible, y en $95 \%$ de los casos proporciona inmunidad efectiva dentro de la primera semana de su aplicación. Se administra por vía subcutánea como una dosis única de $0.5 \mathrm{~mL}$, la reinmunización es requerida cada 10 años para pacientes en riesgo, aunque una dosis única probablemente confiere protección de por vida. Está indicada en todas las personas que vivan en áreas endémicas, viajeros internacionales, personal militar y personal de laboratorios expuesto al virus de la fiebre amarilla (32).

La vacuna contiene virus vivos atenuados que crecen en un medio de huevo de pollo embrionado por lo que puede contener ovoalbúmina (entre $0.13-4.42 \mathrm{mcg} / \mathrm{mL}$ de proteína de ovoalbúmina según la marca) $(33,34)$. El riesgo de anafilaxia es de $0.42-1.8$ casos por 100000 dosis aplicadas y en la mayoría de los casos se considera que es debido al contenido de proteína de huevo presente en la vacuna, por lo cual, la alergia al huevo es una contraindicación para su administración (33-35).

Conclusión. Existen pocos estudios que evalúen la seguridad de la aplicación de la vacuna contra la fiebre amarilla en pacientes con alergia al huevo, sin embargo esta hace parte del esquema nacional de vacunación en Colombia y por lo tanto una valoración previa por alergología para realización de pruebas cutáneas permite que este grupo de pacientes no tengan retrasos ni restricciones injustificadas en su aplicación $(11,15,36)$.

\section{- Mito número 3}

\section{"El timerosal causa autismo"}

Discusión. Desde 1940 el timerosal se ha utilizado como un preservante para inhibir el crecimiento de bacterias y hongos en las preparaciones de vacunas multidosis, sin em- bargo, en 2001 se removió de casi todas las vacunas debido a la preocupación acerca de la neurotoxicidad causada por mercurio $(1,6)$. El timerosal se metaboliza a etilmercurio y difiere al metilmercurio, debido a que tiene un metabolismo rápido y tiempo de vida media más corta, por lo tanto, no se acumula en el cuerpo y no se ha demostrado un efecto tóxico para el sistema nervioso central ni con el desarrollo de enfermedades como el autismo $(37,38)$.

Conclusión. Diferentes trabajos, siguen excluyendo una posible relación entre el timerosal contenido en las vacunas y el desarrollo de autismo (37).

\section{- Mito número 4}

"Las vacunas se relacionan con el desarrollo de enfermedades alérgicas"

Discusión. La asociación entre las vacunas y el riesgo de enfermedades atópicas se propuso por primera vez en 1994 y hoy en día continúan siendo tema de debate. La prevalencia del asma y de enfermedades alérgicas ha venido aumentando en las últimas décadas, una hipótesis es que la vacunación podría predisponer a enfermedades alérgicas debido a la subsecuente reducción de infecciones o por un efecto inmune directo. Sin embargo, los estudios no han logrado demostrar esto (39).

En un estudio retrospectivo, observacional que incluyó más de 18000 pacientes entre 6 y 44 años y cuyo objetivo principal era evaluar el efecto de las vacunas en la incidencia de enfermedades alérgicas no logró demostrar una relación causal entre la vacunación y la incidencia de condiciones alérgicas (40). Timmermann y colaboradores realizaron un estudio prospectivo con el objetivo de determinar si la vacunación con triple viral administrada en la infancia temprana se asociaba con asma y enfermedades alérgicas a la edad de 5,7 y 13 años, encontrando que la administración temprana de esta vacuna puede tener un efecto protector contra la alergia hasta los siete años y contra el asma hasta los 13 años (41).

Conclusión. No se ha logrado establecer una asociación entre la vacunación contra enfermedades inmuno-prevenibles rutinaria durante la infancia y el riesgo de desarrollar una enfermedad alérgica. Por lo tanto, la vacunación es una medida segura.

\section{- Mito número 5}

\section{"La alergia al látex no genera reacciones alérgicas graves"}

Discusión. Algunas vacunas utilizan látex en los tapones de los viales o puede estar presente en las jeringas, esto aumenta el riesgo de reacciones en pacientes con alergia al látex, aunque la incidencia de anafilaxia secundaria al látex a través de esta vía es baja. En general, los niños con anafilaxia por látex no deberían recibir vacunas con viales o jeringas que contengan látex a menos que el beneficio sea 
mayor que el riesgo; sin embargo, los niños con reacciones no anafilácticas podrían recibir estas vacunas, teniendo en cuenta que requieren un periodo de observación luego de la administración de la vacuna y el uso de guantes libres de látex (42-44).

Conclusión. En caso de reacciones severas como la anafilaxia por látex, se recomienda evaluar el riesgobeneficio para la administración de vacunas con tapones que contengan látex.

\section{- Mito número 6}

\section{"La alergia a la gelatina no existe"}

Discusıón. La gelatina puede ser de origen porcino o bovino, se utiliza como estabilizante en vacunas que contienen virus vivos atenuados como: influenza, triple viral, varicela, encefalitis japonesa y herpes zoster; siendo responsable de la mayoría de las reacciones alérgicas asociadas a estas vacunas. Además, cerca del $25 \%$ de los pacientes pueden desarrollar una alergia alimentaria a la gelatina luego de la administración de estas vacunas y por lo tanto un antecedente negativo de alergia a la gelatina no excluye una reacción de hipersensibilidad a la misma. Los pacientes alérgicos a la gelatina tienen alta probabilidad de presentar reacciones de hipersensibilidad inmediata como anafilaxia luego de la administración de vacunas que contienen gelatina; por lo tanto, estos pacientes deben ser evaluados previamente determinando la presencia de IgE específica para gelatina por medio de pruebas séricas o cutáneas. Estas reacciones han disminuido debido a que se removió de muchas vacunas $(11,27,45-48)$.

Conclusión. En los pacientes con sospecha de reacciones de hipersensibilidad inmediata a la gelatina, el primer paso es realizar pruebas alergológicas (pruebas cutáneas y medición de IgE sérica específica), si alguna de las pruebas es positiva se debe evitar la aplicación de la vacuna que contenga gelatina. Si las pruebas son negativas se puede administrar la dosis completa de la vacuna y dejar al paciente 30 minutos en observación luego de la aplicación. En caso de ser necesaria la administración de la misma y el paciente no tenga anticuerpos protectores, se recomienda administrar la vacuna en dosis graduales bajo observación (27).

\section{- Mito número 7}

\section{"La alergia a levaduras no es relevante"}

Discusión. La vacuna contra el virus de la hepatitis B (VHB) y la vacuna contra el virus del papiloma humano (VPH) cuadrivalente son cultivadas en la levadura Saccharomyces cerevisiae. La vacuna del VHB contiene 1-5\% de proteínas de levadura residual, un total por dosis de más de $25 \mathrm{mg}$, mientras que la vacuna cuadrivalente del VPH contiene menos de $7 \mathrm{mcg}$ por dosis. Rara vez una reacción inmediata ocurre luego de la aplicación de la vacuna contra el VHB y el VPH en pacientes alérgicos a la levadura. Aunque la anafilaxia es rara, se reportan alrededor de 2.6 casos por

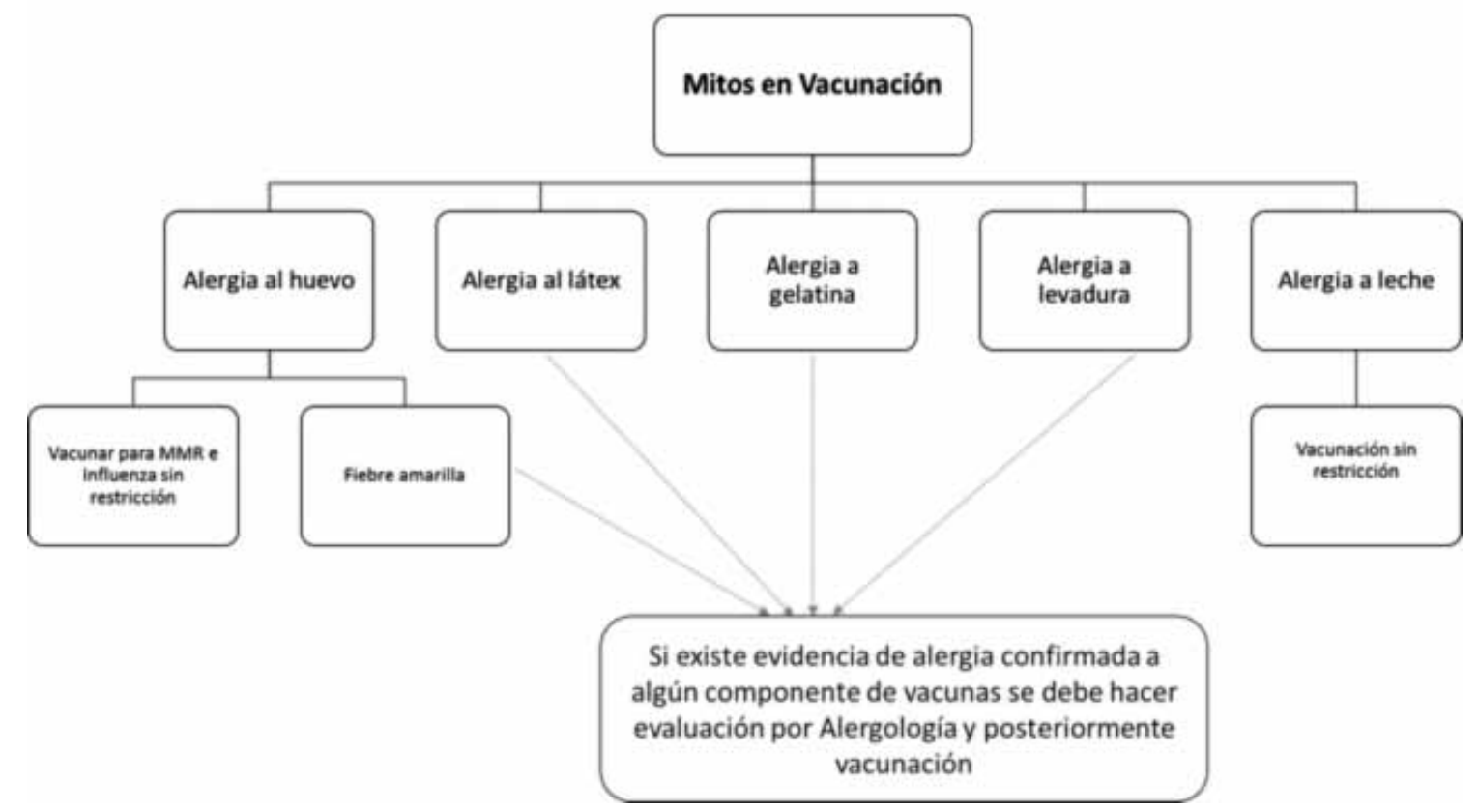

Figura 2. Resumen de la conducta a seguir en los principales mitos en vacunación. 
cada 100000 dosis. Las personas con alergia documentada al S. cerevisiae, tienen contraindicada la aplicación de cualquiera de estas vacunas hasta que se realicen las pruebas alergológicas necesarias $(2,11,49)$.

Conclusión. Los pacientes con sospecha de alergia a la levadura, deben ser estudiados antes de administrar las vacunas contra el VHB y la vacuna cuadrivalente del $\mathrm{VPH}$, por medio de IgE sérica específica para levadura y pruebas cutáneas. En el caso de ser positivas, la vacuna se podría administrar en dosis graduales bajo observación. Si las pruebas son negativas se puede administrar la dosis completa de la vacuna y dejar al paciente 30 minutos en observación luego de la aplicación. $(11,15)$

\section{- Mito número 8}

"Se deben evitar las vacunas que contienen leche en los pacientes que tienen alergia a la proteina de la leche de vaca"

Discusión. Trazas de proteína de leche de vaca pueden estar presente en vacunas contra como la difteria, tétano, tos ferina y polio oral. Las bajas concentraciones de proteína de la leche de vaca, no son suficientes para desencadenar reacciones en los pacientes alérgicos a la proteína de la leche de la vaca $(50,51)$.

Conclusión. Los pacientes alérgicos a la proteína de leche de vaca no requieren precauciones especiales cuando se administran vacunas que contengan trazas de dicha proteína.

\section{Conclusión}

Sin decir que las vacunas son inocuas, los mitos que se han generado frente a ellas y la creación de los movimientos antivacunas, han llevado al resurgimiento de enfermedades que ya se encontraban erradicadas, aumentando morbimortalidad en la población de riesgo y generando costos evitables.

Las reacciones de hipersensibilidad a vacunas tienen baja prevalencia, en caso de presentarse, el paciente debe ser evaluado por el alergólogo, quien definirá según el riesgo/beneficio y luego de los estudios pertinentes, la posibilidad o no de aplicar la vacuna. En conclusión, son muy pocos los casos en los cuales se deba restringir la aplicación de las vacunas en la población infantil y la mayoría de las vacunas se pueden aplicar en los servicios de atención primaria, salvo algunas excepciones que requieren estudio por alergología para no generar retraso en los esquemas de vacunación (Figura 2).

\section{Referencias}

1. OMS, UNICEF BM. Vacunas e inmunización: situación mundial. Vacunas e Inmunización Situación Mundial [Internet]. 2010;Tercera Ed:1-228. Available from: http://apps.who.int/iris/bitstream/10665/44210/1/9789243563862_spa.pdf

2. Echeverría-Zudaire LA, Ortigosa-del Castillo L, Alonso-Lebrero E, ÁlvarezGarcía FJ, Cortés-Álvarez N, García-Sánchez N, et al. Consensus document on the approach to children with allergic reactions after vaccination or allergy to vaccine components. Allergol Immunopathol (Madr). 2015;43(3):304-25.
3. García Sicilia J CM. Generalidades de las vacunas. Asoc Española Pediatr. 2013;1-8.

4. Rashid H, Khandaker G, Booy R. Vaccination and herd immunity: What more do we know? Vol. 25, Current Opinion in Infectious Diseases. 2012. p. 243-9.

5. Sarampión [Internet]. Organización Mundial de la Salud. 2018 [cited 29 January 2018]. Available from: http://who.int/mediacentre/factsheets/fs286/es/

6. Whitney CG, Zhou F, Singleton J, Schuchat A, Centers for Disease Control and Prevention (CDC). Benefits from immunization during the vaccines for children program era-United States, 1994-2013. Vol. 63, MMWR. Morbidity and mortality weekly report. 2014

7. Wakefield A, Murch S, Anthony A, Linnell J, Casson D, Malik M, et al. RETRACTED: Ileal-lymphoid-nodular hyperplasia, non-specific colitis, and pervasive developmental disorder in children. Lancet. 1998;351(9103):637-41.

8. Sathyanarayana Rao T, Andrade C. The MMR vaccine and autism: Sensation, refutation, retraction, and fraud. Indian J Psychiatry. 2011;53(2):95.

9. Clift K, Rizzolo D. Vaccine myths and misconceptions. J Am Acad Physician Assist. 2014;27(8):21-5.

10. Wood RA. Allergic reactions to vaccines. Pediatr Allergy Immunol. 2013;24(6):521-6.

11. Dreskin SC, Halsey NA, Kelso JM, Wood RA, Hummell DS, Edwards KM, et al. International Consensus (ICON): allergic reactions to vaccines. World Allergy Organ J. 2016;1-21.

12. Rüggeberg JU, Gold MS, Bayas JM, Blum MD, Bonhoeffer J, Friedlander $\mathbf{S}$, et al. Anaphylaxis: Case definition and guidelines for data collection, analysis, and presentation of immunization safety data. Vaccine. 2007;25(31):5675-84.

13.Zhou W, Pool V, Iskander JK, English-Bullard R, Ball R, Wise RP, et al. Surveillance for safety after immunization: Vaccine Adverse Event Reporting System (VAERS)--United States, 1991-2001. MMWR Surveill Summ Morb Mortal Wkly report Surveill Summ / CDC. 2003;52(1):1-24.

14. McNeil MM, Weintraub ES, Duffy J, Sukumaran L, Jacobsen SJ, Klein NP, et al. Risk of anaphylaxis after vaccination in children and adults. J Allergy Clin Immunol. 2016;137(3):868-78.

15. Nilsson L, Brockow K, Alm J, Cardona V, Caubet JC, Gomes E, et al. Vaccination and allergy: EAACI position paper, practical aspects. Vol. 28, Pediatric Allergy and Immunology. 2017. p. 628-40.

16. Chung EH. Vaccine allergies. Clin Exp Vaccine Res. 2014;3(1):50-7.

17. Fritsche PJ, Helbling A, Ballmer-Weber BK. Vaccine hypersensitivity--update and overview. Swiss Med Wkly. 2010 May;140(17-18):238-46.

18. Caubet JC, Ponvert C. Vaccine Allergy. Vol. 34, Immunology and Allergy Clinics of North America. 2014. p. 597-613.

19. Bergfors E, Hermansson G, Nyström Kronander U, Falk L, Valter L, Trollfors B. How common are long-lasting, intensely itching vaccination granulomas and contact allergy to aluminium induced by currently used pediatric vaccines? A prospective cohort study. Eur J Pediatr. 2014;173(10):1297-307.

20. Halperin SA, Eastwood BJ, Barreto L, Friesen B, Medd L, Meekison W, et al. Adverse reactions and antibody response to four doses of acellular or whole cell pertussis vaccine combined with diphtheria and tetanus toxoids in the first 19 months of life. Vaccine. 1996;14(8):767-72.

21. Pichichero ME, Edwards KM, Anderson EL, Rennels MB, Englund JA, Yerg DE, et al. Safety and immunogenicity of six acellular pertussis vaccines and one whole-cell pertussis vaccine given as a fifth dose in four- to six-year-old children. Pediatrics. 2000;105(1):e11.

22.Smith M. Vaccine Safety: Medical Contraindications, Myths, and Risk Communication. Pediatr Rev. 2015 Jun;36(6):227-38.

23. Fine PEM. Herd immunity: history, theory, practice. Epidemiol Rev. 1993;15(2):265

24.Zeiger RS. Current issues with influenza vaccination in egg allergy. Vol. 110, Journal of Allergy and Clinical Immunology. 2002. p. 834-40.

25. Kelso JM. Safety of influenza vaccines. Vol. 12, Current Opinion in Allergy and Clinical Immunology. 2012. p. 383-8.

26. Belshe RB, Ambrose CS, Yi T. Safety and efficacy of live attenuated influenza vaccine in children 2-7 years of age. Vaccine. 2008;26(SUPPL. 4).

27. Kelso JM, Greenhawt MJ, Li JT, Nicklas RA, Bernstein DI, Blessing-Moore J, et al. Adverse reactions to vaccines practice parameter 2012 update. J Allergy Clin Immunol. 2012;130(1):25-43.

28. Turner PJ, Southern J, Andrews NJ, Miller E, Erlewyn-Lajeunesse M. Safety of live attenuated influenza vaccine in young people with egg allergy: multicentre prospective cohort study. BMJ. 2015;351:h6291.

29. Immunization NNAC on. Chapter on Influenza and Statement on Seasonal Influenza Vaccine for 2016-2017. In: Canadian Immunization Guide. 2015.

30. Centers for Disease Control and Prevention. Prevention of measles, rubella, congenital rubella syndrome, and mumps, 2013: summary recommendations of the 
Advisory Committee on Immunization Practices (ACIP). Mmwr. 2013;62(4):1-34.

31. Cronin J, Scorr A, Russell S, McCoy S, Walsh S, O'Sullivan R. A review of a paediatric emergency department vaccination programme for patients at risk of allergy/anaphylaxis. Acta Paediatr. 2012;101(9):941-5.

32. Monath TP. Yellow Fever. In: Plotkin SA, Orenstein WA, editors. Vaccines. W.B. Saunders Company; 1999. pp. 815-879.

33. Smith D, Wong P, Gomez R, White K. Ovalbumin content in the yellow fever vaccine. J Allergy Clin Immunol Pract. 2015;3(5):794-5.

34. Rutkowski K, Ewan PW, Nasser SM. Administration of yellow fever vaccine in patients with egg allergy. Int Arch Allergy Immunol. 2013;161(3):274-8.

35. Pasteur S. Yellow Fever Vaccine. Sanofi Pasteur LE6103-LE6104. 2001;(June):17.

36. Echeverría Zudaire L, Ortigosa Del Castillo L, Alonso Lebrero E, Álvarez García FJ, Cortés Álvarez N, García Sánchez N, et al. Documento de consenso sobre la actitud ante un niño con una reacción alérgica tras la vacunación o alergia a componentes vacunales. An Pediatr. 2015;83(1):63.e1-63.e10.

37. Principi N, Esposito $\mathbf{S}$. Adverse events following immunization: real causality and myths. Expert Opin Drug Saf. 2016;15(6):825-35.

38. Muñoz M A, Abarca V K, Jiménez de la J J, Luchsinger F V, O'Ryan G M, Ripoll M E, et al. Seguridad de las vacunas que contienen timerosal: Declaración del Comité Consultivo de Inmunizaciones (CCI) de la Sociedad Chilena de Infectología. Rev Chil infectología. 2007;24(5):372-6.

39. Matheson MC, Haydn Walters E, Burgess J a, Jenkins M a, Giles GG, Hopper JL, et al. Childhood immunization and atopic disease into middle-age--a prospective cohort study. Pediatr Allergy Immunol. 2010;21(2 Pt 1):301-6.

40. Dulny G, Sybilski AJ, Zalewska M, Raciborski F, Komorowski J, Piekarska B, et al. The effect of preventive immunization on the incidence of allergic conditions. Iran J Allergy, Asthma Immunol. 2015;14(4):402-9.

41. Timmermann CAG, Osuna CE, Steuerwald U, Weihe P, Poulsen LK, Grandjean P. Asthma and allergy in children with and without prior measles, mumps, and rubella vaccination. Pediatr Allergy Immunol. 2015;26(8):742-9.
42. Caubet JC, Rudzeviciene O, Gomes E, Terreehorst I, Brockow K, Eigenmann PA. Managing a child with possible allergy to vaccine. Pediatr Allergy Immunol. 2014;25(4):394-403

43. Russell M, Pool V, Kelso JM, Tomazic-Jezic VJ. Vaccination of persons allergic to latex: A review of safety data in the Vaccine Adverse Event Reporting System (VAERS). Vol. 23, Vaccine. 2004. p. 664-7.

44. Hamilton RG, Brown RH, Veltri MA, Feroli ER, Primeau MN, Schauble JF, et al. Administering pharmaceutical to latex-allergic patients from vials containing natural rubber latex closures. Vol. 62, American Journal of Health-System Pharmacy. 2005. p. 1822-7.

45. Sakaguchi M, Inouye S. IgE sensitization to gelatin: The probable role of gelatin-containing diphtheria-tetanus-acellular pertussis $(\mathrm{DTaP})$ vaccines. Vaccine. 2000;18(19):2055-8.

46. Kelso JM, Jones RT, Yunginger JW. Anaphylaxis to measles, mumps, and rubella vaccine mediated by IgE to gelatin. J Allergy Clin Immunol. 1993;91(4):867-72.

47. Kuno-Sakai H, Kimura M. Removal of gelatin from live vaccines and DTaP-An ultimate solution for vaccine-related gelatin allergy. Biologicals. 2003;31(4):2459.

48. Sakaguchi M, Nakayama T, Inouye S. Food allergy to gelatin in children with systemic immediate-type reactions, including anaphylaxis, to vaccines. $J$ Allergy Clin Immunol. 1996;98(6 I): 1058-61.

49. DiMiceli L, Pool V, Kelso JM, Shadomy S V., Iskander J. Vaccination of yeast sensitive individuals: Review of safety data in the US vaccine adverse event reporting system (VAERS). Vaccine. 2006;24(6):703-7.

50. Parisi CAS, Smaldini PL, Gervasoni ME, Maspero JF, Docena GH. Hypersensitivity reactions to the Sabin vaccine in children with cow's milk allergy. Clin Exp Allergy. 2013;43(2):249-54.

51. Kattan JD, Konstantinou GN, Cox AL, Nowak-Wgrzyn A, Gimenez G, Sampson HA, et al. Anaphylaxis to diphtheria, tetanus, and pertussis vaccines among children with cow's milk allergy. Vol. 128, Journal of Allergy and Clinical Immunology. 2011.p. 215-8. 